Utilização do Sig na Delimitação das Áreas de Preservação Permanente (APP's) na Bacia do Rio Sagrado (Morretes/PR) Alexei Nowatzki, Leonardo José Cordeiro Santos, Eduardo Vedor de Paula

\title{
UTILIZAÇÃO DO SIG NA DELIMITAÇÃO DAS ÁREAS DE PRESERVAÇÃO PERMANENTE (APP's) NA BACIA DO RIO SAGRADO (MORRETES/PR)
}

\section{Use of Gis in the Delimitation of Mandatory Preservation Areas in the Hydrographic Basin of Sagrado River (Morretes/PR)}

\author{
Alexei Nowatzki \\ Graduando em Geografia pela Universidade Federal Paraná (bolsista IC - CNPq) \\ Curitiba/PR - Brasil \\ alexei.geografia@ufpr.br \\ Leonardo José Cordeiro Santos \\ Prof. Dr. Depto. de Geografia da Universidade Federal Paraná \\ Pesquisador do CNPq (bolsista produtividade) \\ Curitiba/PR - Brasil \\ santos@ufpr.br \\ Eduardo Vedor de Paula \\ Geógrafo, doutorando em Geografia pela UFPR (bolsista DTI - 1 CNPq) \\ Curitiba/PR - Brasil \\ edugeo@ufpr.br
}

Artigo recebido para publicação em 14/01/2010 e aceito para publicação em 28/03/2010

RESUMO: $\quad$ O presente trabalho se enquadra no Programa CAD (Contaminantes, Assoreamento e Dragagem) no Estuário de Paranaguá/PR, tendo por objetivo a utilização do SIG (Sistema de Informações Geográficas) para a delimitação das Áreas de Preservação Permanente (APP's), na bacia hidrográfica do Rio Sagrado (Morretes/PR). Como etapa preliminar efetuou-se o estudo da legislação brasileira vigente (Código Florestal e resoluções CONAMA) no que se refere à delimitação das APP's. Em seguida, por meio do software ArcGIS 9.2, foram delimitadas as seguintes categorias de APP: 1) nascentes, 2) mata ciliar, 3) entorno de reservatórios, 4) topo de morros, 5) topo de montanhas, 6) linhas de cumeada, 7) encostas acima de 45 graus de declividade e 8) mangues. A utilização do SIG mostrou-se uma eficiente ferramenta para delimitação das Áreas de Preservação Permanente, a partir dos resultados verificouse a existência de dois grupos de APP's: o primeiro representado pelo conjunto das categorias 1, 2, 3 e $8 \mathrm{com} 51,9 \%$ do total mapeado e um segundo representado pelo conjunto das categorias 4, 5, 6 e 7, com 48,1\% do total das APP's da bacia. A APP de Mata Ciliar possui a maior representatividade com $28,9 \mathrm{~km}^{2}$ tendo como principal funcionalidade ambiental a preservação dos recursos hídricos.

Palavras-chave: Bacia hidrográfica do rio Sagrado. Áreas de Preservação Permanente. Sistema de Informações Geográficas.

ABSTRACT: This paper fits within the CAD program (Contaminants, Siltation and Dredging in the estuary of Paranaguá/PR) purposing the application of GIS (Geographic Information System) in delimitation 
Utilização do Sig na Delimitação das Áreas de Preservação Permanente (APP’s) na Bacia do Rio Sagrado (Morretes/PR)

Alexei Nowatzki, Leonardo José Cordeiro Santos, Eduardo Vedor de Paula

of Mandatory Preservation Areas (APP's) in the hydrographic basin of Sagrado River (Morretes/PR). As a preliminary stage, it was effectuated the study of the current Brazilian legislation (Forest Code and CONAMA resolutions) concerning to the delimitation of Mandatory Preservation Areas (APP's). Then, using the software ArcGis 9.2, it was delimitated the following classes of APP: 1) water spring, 2) riparian forest, 3) around tanks, 4) top of hills 5) top of mountains, 6) ridge lines, 7) slopes above 45 degrees and 8) mangroves. The application of GIS proved to be an efficient tool for the Mandatory Preservation Areas' delimitation, from the results it was verified the existence of two APP's groups: the first one represented by the set of categories 1,2,3 and 8 with 51,9\% of the whole mapping, and a second group witch is represented by the set of categories 4, 5, 6 and 7, with 48,1\% total of the basin's APP's. The riparian forest APP has the biggest representation, with $28,9 \mathrm{~km}^{2}$ having as the main environmental functionality the preservation of water resources.

Keywords: Sagrado drainage basin. Mandatory Preservation Areas. Geographic Information System.

\section{INTRODUÇÃO}

No litoral do Estado do Paraná o assoreamento atinge áreas de navegação portuária nas baías de Antonina e de Paranaguá e as dragagens constituem as principais soluções adotadas pelo Estado na tentativa de solucionar este problema, mas, o seu alto custo de execução, atrelado à dificuldade de se licenciar áreas de despejo, vêm tornando esta estratégia inviável. Para se entender melhor o processo de assoreamento, deve-se localizar quais são as áreas fontes de sedimentos dentro das bacias hidrográficas que drenam para as baías do litoral e a sua dinâmica no contexto hidrográfico. Nesta perspectiva o Programa CAD (Contaminantes, Assoreamento e Dragagem) no Estuário de Paranaguá, vem sendo desenvolvido desde 2005, conforme descrevem Boldrini e Paula (2008), tomando como unidades de planejamento as bacias hidrográficas que drenam para as referidas baías.

Uma das principais causas do assoreamento nas baías do Paraná é a retirada da vegetação natural das Áreas de Preservação Permanente (APP's). De acordo com a legislação brasileira, uma APP deve ser um espaço físico-natural protegido, sem qualquer atividade, contudo, nem sempre estas APP's são respeitadas no litoral paranaense e inúmeras atividades humanas foram implantadas ao longo dos anos em locais aonde deveria se preservar.
De um modo geral os mapeamentos efetuados contemplam somente as nascentes e as matas ciliares, em função da maior facilidade de se efetuar sua delimitação e da importância dessas duas categorias de APP's na preservação dos recursos hídricos, conforme apresentam Mascarenhas et al. (2009). A utilização do Sistema de Informações Geográficas (SIG) pode ser uma excelente ferramenta, visto que os mapeamentos podem ser realizados e com maior precisão, além de permitir a delimitação das demais categorias que na legislação se apresentam de uma forma subjetiva, como é o caso das Linhas de Cumeada, Topos de Morros e de Montanhas (RIBEIRO et al., 2005; NEVES et al. 2009).

O objetivo do presente trabalho é utilizar o SIG para delimitação das APP's na bacia do Rio Sagrado, localizada no município litorâneo de Morretes, Paraná com 137,7 km² entre o a Serra do Mar e a Planície Litorânea (FIGURA 1). A litologia na Serra do Mar tem o predomínio de rochas do Complexo Gnáissico-Migmitítico e Cambissolos Háplicos associados à Neossolos Litólicos, enquanto que na planície predominam solos hidromórficos sobre sedimentos do quaternário. A precipitação é de $2.000 \mathrm{~mm}$ anuais na planície e estima-se que nas porções de serra o acumulado anual supere os $3.000 \mathrm{~mm}$ (PAULA et al, 2006).

Resultados prévios do Programa CAD 
Utilização do Sig na Delimitação das Áreas de Preservação Permanente (APP's) na Bacia do Rio Sagrado (Morretes/PR) Alexei Nowatzki, Leonardo José Cordeiro Santos, Eduardo Vedor de Paula

(PAULA et al., 2006; PAULA e CUNICO, 2007) mostraram que dentre as bacias hidrográficas que drenam para a baía de Antonina, a bacia do rio Sagrado é a que revela maior percentual de uso agropecuário, bem como uma significativa densidade de estradas rurais mal implantadas. Quando estes usos se situam em áreas de APP's, devido à suscetibilidade das mesmas, conforme enfatizado no Código Florestal Brasileiro, acarreta no desenvolvimento de processos erosivos, os quais podem intensificar o assoreamento dos rios e consequentemente das baías de Antonina e de Paranaguá.

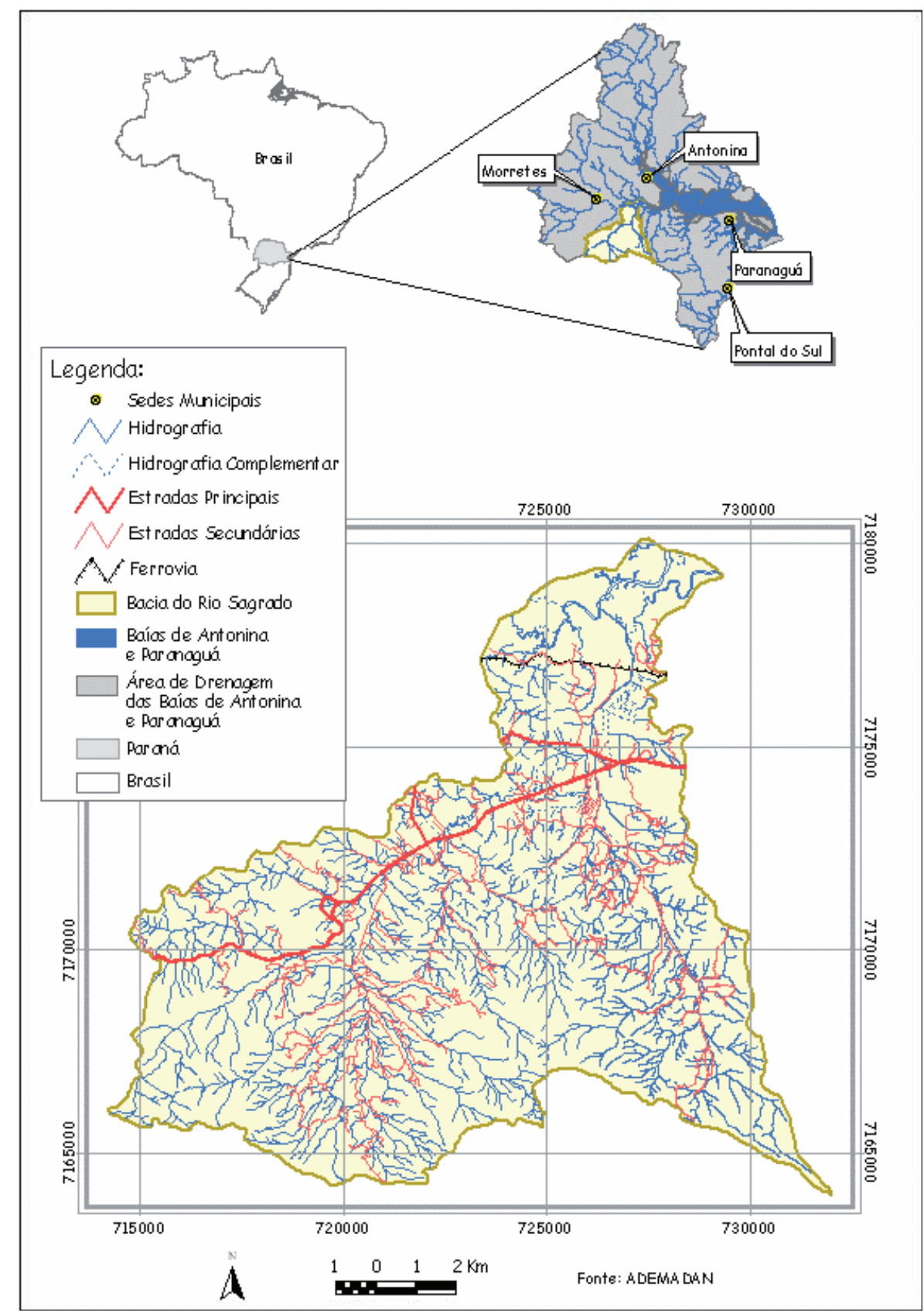

FIGURA 1: Localização da bacia hidrográfica do Rio Sagrado, Paraná. 
Utilização do Sig na Delimitação das Áreas de Preservação Permanente (APP’s) na Bacia do Rio Sagrado (Morretes/PR)

Alexei Nowatzki, Leonardo José Cordeiro Santos, Eduardo Vedor de Paula

\section{A LEGISLAÇÃO AMBIENTAL BRASILEIRA REFERENTE ÀS ÁREAS DE PRESERVAÇÃO PERMANTENTE}

No Brasil, os mecanismos legais associados à preservação do meio ambiente entraram em vigor com o Código Florestal Brasileiro de 1965. Dentro deste quadro de leis, as APP's são considerados espaços físicos legalmente protegidos, estando devidamente definidos nos termos dos Artigos $2^{\circ}$ e $3^{\circ}$ da Lei 4.771/65 (Código Florestal Brasileiro). Estas áreas, em geral são cobertas por vegetação nativa, tendo a função ambiental de preservar os recursos hídricos, a paisagem, a estabilidade geológica, a biodiversidade, o fluxo gênico de fauna e flora, proteger o solo e assegurar o bem-estar das populações humanas. É de suma importância a preservação destes espaços, pois eles prestam "serviços" aos ecossistemas que eles estão inseridos. Mascarenhas et al. (2009) argumenta que "a legislação ambiental brasileira apresenta vários institutos que visam à proteção do meio ambiente. Essa preocupação encontra-se presente na Constituição Federal, em seu artigo 225, que garante a todos o direito ao meio ambiente ecologicamente equilibrado".

No que se refere às APP's, o Código Florestal Brasileiro apresenta oito categorias passiveis de serem delimitadas de acordo com fatores hidrológicos e com aspectos naturais da paisagem em conformidade com a disposição e a caracterização geomorfológica do ambiente. Conforme o Artigo $2^{\circ}$ da Lei 4.771/65 as oito categorias são:

1) Ao longo dos rios ou qualquer curso de água, em faixa marginal, cuja largura mínima será: a) de 30 metros para rios de menos de 10 metros de largura;

b) de 50 metros para cursos de 10 a 50 metros de largura;

c) de 100 metros para cursos de 50 a 200 metros de largura;

d) de 200 metros para cursos de 200 a 600 metros de largura;

e) de 500 metros para cursos que tenham largura acima de 600 metros de largura.
2) Em um raio de 50 metros de nascentes;

3) Ao redor de lagoas, lagos ou reservatórios d'água, mesmo que artificiais;

4) No topo de morros, montes, montanhas e serras;

5) Em encostas com declividade superior a 45 graus, equivalente a $100 \%$ na linha de maior declive;

6) Nas restingas, como fixadoras de dunas ou estabilizadoras de mangues;

7) Nas bordas dos tabuleiros ou chapadas; e,

8) Em altitude superior a 1.800 metros.

Em março de 2002, o Conselho Nacional do Meio Ambiente (CONAMA) cria as Resoluções 302 e 303, que estabelecem parâmetros, definições e limites referentes às Áreas de Preservação Permanente, complementando o Código Florestal Brasileiro criado em 1965.

Na Resolução 303 aparece pela primeira vez o limite para APP's em torno de reservatórios artificiais e lagoas naturais. De acordo com esta resolução, as áreas urbanas consolidadas devem ter um raio de 30 metros. Para áreas rurais o raio é de e 15 metros, exceto corpos hídricos com mais de 20 hectares de superfície que devem possuir um raio de cem metros de APP.

No contexto geomorfológico da bacia do rio Sagrado, a resolução em questão também estabelece APP nos locais situados:

1) Ao redor de nascente ou olho d'água, ainda que intermitente, com raio mínimo de cinquenta metros de tal forma que proteja, em cada caso, a bacia hidrográfica contribuinte;

2) Nas linhas de cumeada, em área delimitada a partir da curva de nível correspondente a dois terços da altura, em relação à base do pico mais baixo da cumeada, fixando-se a curva de nível para cada segmento da linha de cumeada equivalente a mil metros;

3) Em manguezal, em toda a sua extensão;

Sociedade \& Natureza, Uberlândia, 22 (1): 107-120, abr. 2010 


\section{MATERIAIS E MÉTODOS}

3.1. Delimitação das Áreas de Preservação Permanente da Bacia Rio Sagrado em Ambiente SIG

Para a delimitação das Áreas de Preservação Permanente na bacia do rio Sagrado tomou-se por referência o Código Florestal Brasileiro (BRASIL, 2001), a Resolução CONAMA 302/02 (BRASIL, 2002a) e a Resolução CONAMA 303/02 (BRASIL, 2002b).
A base cartográfica usada contemplou os dados, referentes às curvas de nível, pontos cotados, hidrografia e algumas toponímias, produzidos pelo DSG (Departamento de Serviço Geográfico) em 2002 na escala 1:25.000, editados por Paula e Cunico (2006). Com o auxilio do software ArcGIS 9.2 efetuou-se a confecção do MDT (Modelo Digital do Terreno) e a delimitação das APP's. Todas as categorias consideradas de APP's presentes na bacia do Rio Sagrado estão contempladas na TABELA 1.

TABELA 1: Categorias consideradas para a delimitação de APP na Bacia do rio Sagrado.

\begin{tabular}{|c|c|c|}
\hline CÓDIGO & CATEGORIA & LEGISLAÇÃO \\
\hline APP1 & 50 metros no entorno das nascentes (surgências hídricas) & Lei Federal 4.771/65 \\
\hline APP2a & 30 metros para rios de menos de 10 metros de largura & Lei Federal 4.771/65 \\
\hline $\mathrm{APP} 2 \mathrm{~b}$ & 50 metros para cursos de 10 a 50 metros de largura & Lei Federal 4.771/65 \\
\hline $\mathrm{APP} 2 \mathrm{c}$ & 100 metros para cursos de 50 a 200 metros de largura & Lei Federal 4.771/65 \\
\hline APP3 & 15 metros no entorno de reservatórios artificiais (área rural) & $\begin{array}{c}\text { CONAMA } \\
\text { Resolução 302/02 } \\
\end{array}$ \\
\hline APP4 & $\begin{array}{l}\text { Topo de morros (cota máxima em relação à base entre } 50 \text { e } 300 \\
\text { metros) }\end{array}$ & $\begin{array}{c}\text { CONAMA } \\
\text { Resolução 303/02 }\end{array}$ \\
\hline APP5 & $\begin{array}{l}\text { Topo de montanhas (cota máxima em relação à base superior a } \\
300 \text { metros) }\end{array}$ & $\begin{array}{c}\text { CONAMA } \\
\text { Resolução 303/02 }\end{array}$ \\
\hline APP6 & $\begin{array}{c}\text { Linhas de cumeada (terço superior do pico mais baixo em } \\
\text { segmentos de } 1.000 \text { metros) }\end{array}$ & $\begin{array}{c}\text { CONAMA } \\
\text { Resolução 303/02 }\end{array}$ \\
\hline APP7 & Encostas com declividade superior a 45 graus & Lei Federal 4.771/65 \\
\hline APP8 & Manguezais & $\begin{array}{c}\text { CONAMA } \\
\text { Resolução 303/02 }\end{array}$ \\
\hline
\end{tabular}

Teixeira e Christofoletti (1997) demonstram que em SIG "buffer" significa uma forma de análise de proximidade onde zonas de uma determinada dimensão são delimitadas em volta de uma feição ou de um elemento geográfico, levando-se em conta um determinado atributo. A partir desta técnica, é possível estipular uma área circular na qual representa um entorno necessário para que a nascente com vegetação não perca a sua funcionalidade de manter fluxos regulares de água do lençol freático aflorante para a superfície. Para a delimitação desta categoria de APP, utilizou-se a ferramenta Create Buffers, disponível no software ArcGIS 9.2.

A delimitação das APP's no entorno das nascentes (APP1) foi efetuada a partir da localização de todas as nascentes internas à bacia, seguida da criação de pontos em formato shapefile no ArcGIS 
9.2. Tendo estes pontos confeccionou-se buffers de 50 metros, nas 731 cabeceiras de canais de primeira ordem, existentes na bacia do rio Sagrado e mapeadas na escala 1:25.000.

Para a delimitação das APP's no entorno da rede de drenagem (APP2 "a", "b" e "c") da bacia selecionada, utilizou-se também a ferramenta Create Buffers. A distância especificada para a confecção dos buffers ao longo dos rios foi proporcional à largura aproximada dos mesmos. Para cursos d'água com largura inferior a 10 metros os buffers apresentavam 30 metros (APP2a). No caso dos rios cuja largura apresentou-se entre 10 e 50 metros foram construídos buffers de 50 metros (APP2b). Enquanto que para os trechos de drenagem com largura superior a 50 metros, porém inferior a 200 metros, foram gerados buffers de 100 metros (APP2c). A etapa final do mapeamento da categoria APP2 configurou na exclusão da área de sobreposição desta com a categoria APP1.

A categoria APP3 refere-se à delimitação das APP's no entorno dos 18 reservatórios artificiais existentes na área em análise. O buffer gerado foi correspondente a 15 metros no entorno dos reservatórios.

Na FIGURA 2 estão ilustrados exemplos da abrangência das APP's 1 e 2 .

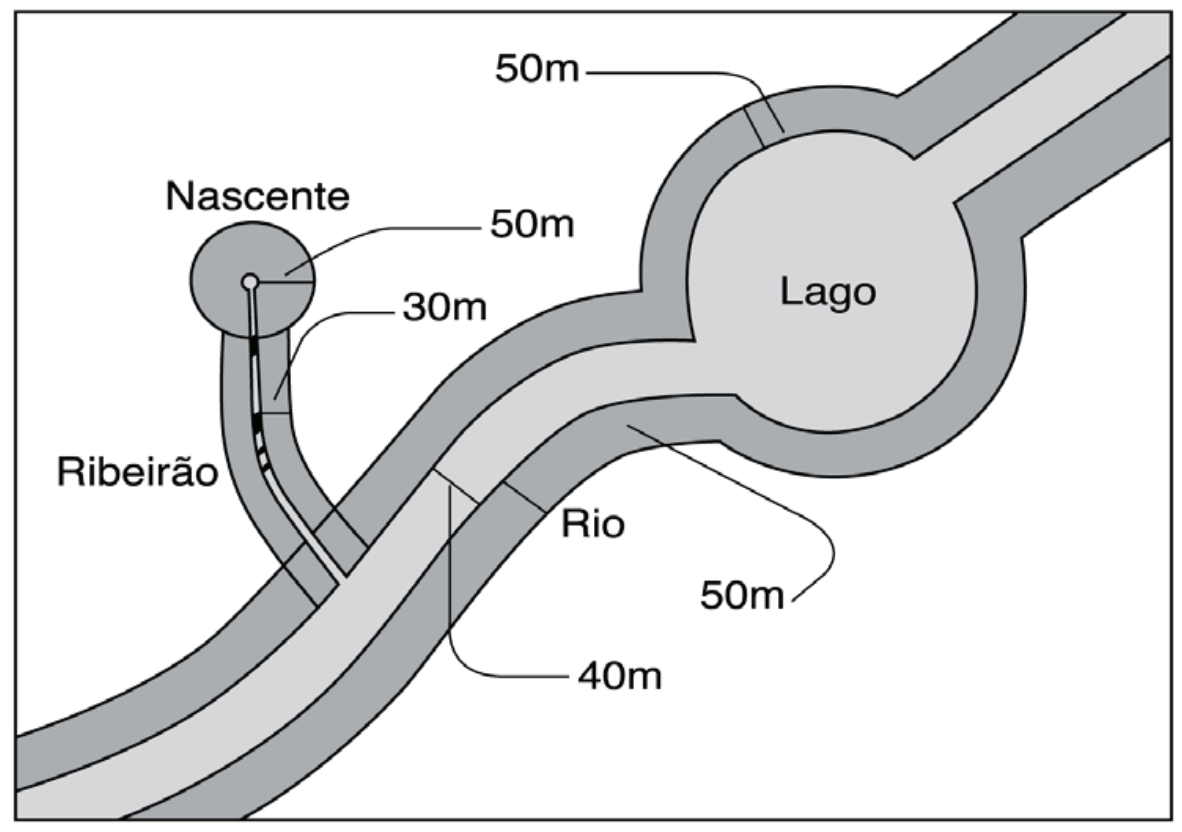

FIGURA 2: Abrangência das APP's conforme a localização dos recursos hídricos. Adaptado de: IEMA/ES (2010).

De acordo com a Resolução CONAMA 303/02 morro é definido como "elevação do terreno com cota de topo em relação à base entre 50 e 300 metros e declividade na encosta de maior declive maior que 30\%". Para a delimitação da categoria "Topo de Morros" (APP4), seguiram-se os seguintes passos:
1) Identificação dos topos isolados ao longo de toda bacia do rio Sagrado

2) Os pontos cotados relativos às altitudes dos picos isolados foram selecionados;

3) A base de cada pico isolado foi definida a partir da depressão mais baixa, interna à área de contribuição do respectivo pico;

4) Depois de calculada a altura dos morros 
potenciais (Pico - Base), manteve-se a seleção somente daqueles cujo valor demonstrou-se entre 50 e 300 metros.

5) Foram considerados morros dentre os picos restantes, somente aqueles cuja declividade em pelo uma de suas vertentes demonstrouse superior a $30 \%$;

6) Em planilha Microsoft Excel foram calculadas as cotas altimétricas relativas ao terço superior, por meio da equação: ((Pico Base) (3) x 2) + Base);

7) Em seguida, para cada morro, sobre o MDT (Modelo Digital do Terreno) e com o auxílio da ferramenta Contour do software ArcGIS 9.2, foi gerada a linha de cota relativa ao terço superior;
8) Esta linha foi convertida em shapefile e transformada em polígono por meio de ferramentas disponíveis na extensão do ArcGIS 9.2, denominada XTools Pro 2.2.0;

9) Por fim, nas áreas em que ocorreu sobreposição de APP4 com APP1, APP2 ou APP3, por meio de recursos existentes na ferramenta Analysis Tools, efetuou-se a exclusão da categoria APP4, sendo mantida, portanto a categoria APP1, APP2 ou APP3.

AFIGURA 3 apresenta um modelo hipotético de um Morro com base na cota $0 \mathrm{~m}$ e topo de $90 \mathrm{~m}$. Seguindo a metodologia supracitada, o seu terço superior estaria demarcado pela cota de $60 \mathrm{~m}$, e todas as áreas situadas acima deste limite seriam Área de Preservação Permanente.

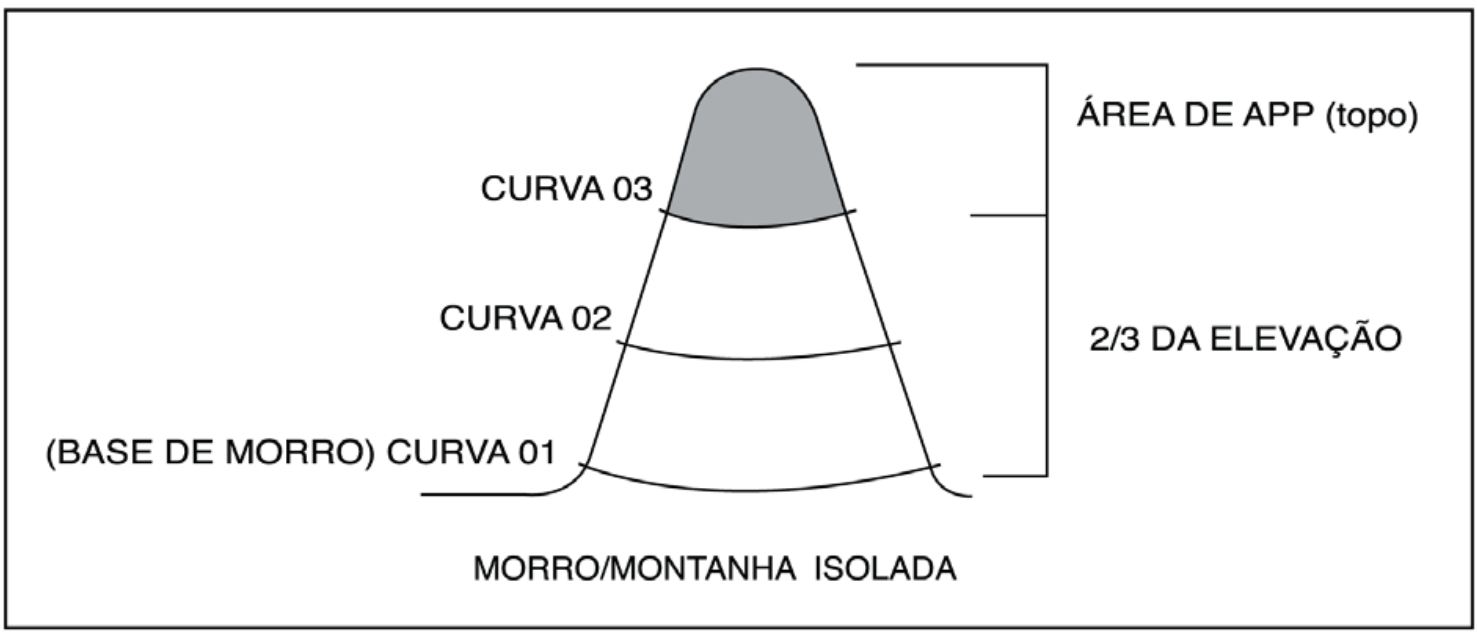

FIGURA 3: Modelo hipotético de delimitação de APP em Morros.

Para a delimitação da categoria APP5 (Montanhas), seguiu-se a metodologia empregada para a categoria APP4, contudo, a altura considerada entre o topo e a base deve ser superior a 300 metros, tendo como base a Resolução CONAMA 303/02.

De acordo com a mesma resolução, as linhas de cumeada (APP6) correspondem a uma sequência de morros (e/ou montanhas) distando a menos de 500 metros um do outro, que em geral situam-se nos divisores das drenagens principais. Também considera que seja delimitada "a partir da curva de nível correspondente a dois terços de altura, em relação à base do pico mais baixo da cumeada, fixando-se a curva de nível para cada segmento da linha de cumeada equivalente a mil metros". A FIGURA 4 apresenta um esquema para delimitação desta categoria. 
Utilização do Sig na Delimitação das Áreas de Preservação Permanente (APP’s) na Bacia do Rio Sagrado (Morretes/PR)

Alexei Nowatzki, Leonardo José Cordeiro Santos, Eduardo Vedor de Paula

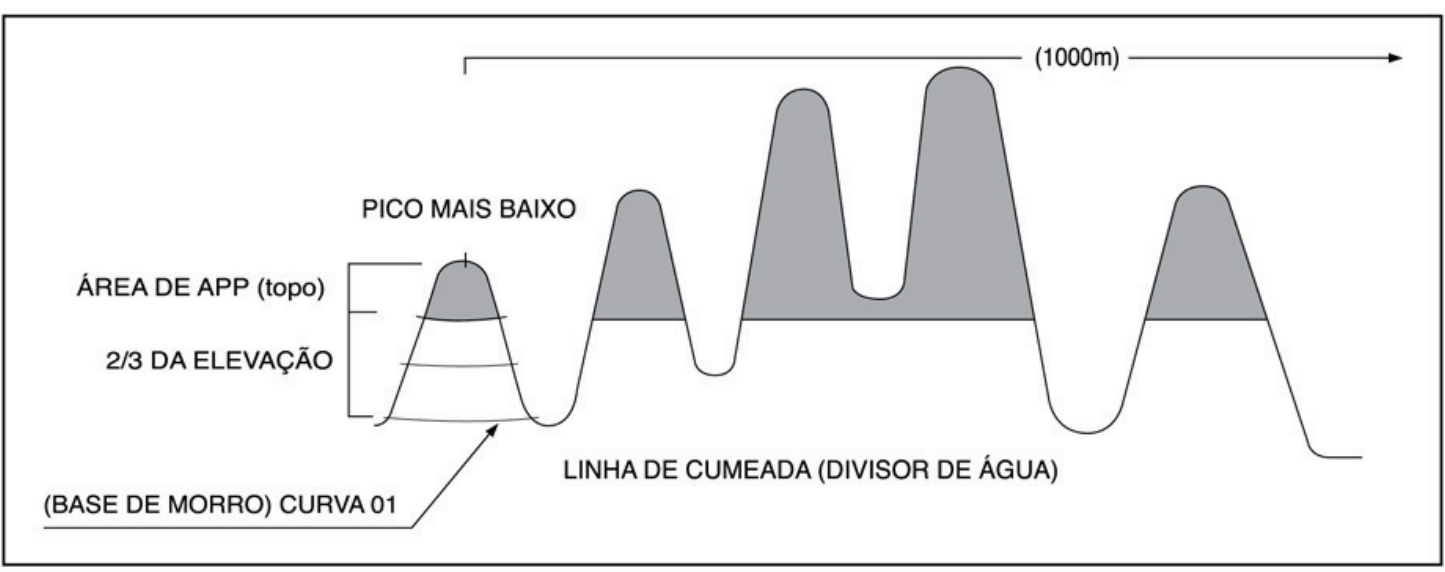

FIGURA 4: Esquema da abrangência das APP's segundo resolução 303/02 do CONAMA.

Para delimitação da APP6 seguiram-se os seguintes passos:

1) Delimitação das bacias de terceira ordem conforme Strahler (1952) apud Christofoletti (1974), com o objetivo de facilitar a identificação das linhas de cumeada;

2) Identificação e traçado das linhas de cumeada sobre o MDT;

3) A base de cada linha de cumeada foi definida a partir da depressão mais baixa, interna à área de contribuição da respectiva cadeia de picos;

4) As linhas de cumeada traçadas foram segmentadas a cada $1 \mathrm{~km}$;

5) Identificação do topo mais baixo a cada $1 \mathrm{~km}$;

6) A cota de preservação foi calculada a cada $1 \mathrm{~km}$, por meio da equação: (((pico mais baixo - base) (3) x 2) + base);

7) Na sequência, para cada linha de cumeada, sobre o MDT, foi gerada a linha de cota relativa ao terço superior;

8) No caso das linhas de cumeada com extensão superior a $1 \mathrm{~km}$, obtiveram-se mais de uma linha relativa ao terço superior, assim fez-se necessária a edição manual das mesmas, de tal forma que a cadeia de morros e montanhas apresentasse somente uma linha de APP;

9) Esta linha foi convertida em formato shapefile e transformada em polígono por meio de ferramentas disponíveis na extensão XTools Pro 2.2.0;
10) Como etapa final, nas áreas em que ocorreu sobreposição de APP6 com as demais APP's previamente delimitadas efetuou-se a exclusão da categoria APP6, sendo mantidas as demais categorias.

A delimitação da APP7 referente às declividades acima de $45^{\circ}$ foi obtida a partir do MDT gerado para a bacia. Das informações de declividade foram selecionadas somente as porções com valores iguais ou superiores a $45^{\circ}$ (equivalentes a $100 \%$ ). Tais porções foram convertidas para o formato shapefile e incluídas na carta de APP's.

Por fim, foram considerados os manguezais (APP8). A delimitação destas APP's foi realizada a partir dos polígonos referentes aos manguezais contidos na carta digital de Cobertura Vegetal e Uso da Terra da área de drenagem das baías de Antonina e Paranaguá, publicada em (PARANÁ, 2002), elaborada a partir de imagens do satélite LANDSAT ETM 7, referentes ao ano de 1999.

Ainda dentro do contexto do Código Florestal Brasileiro, existem as porções de terreno que apresentam declividades entre $25^{\circ}$ e $45^{\circ}$. Estas são consideradas Áreas de Uso Restrito (AUR). Perico e Cemin (2006) apontam que em AUR não é permitida a derrubada de florestas, só sendo tolerada a extração de toras quando em regime de utilização racional, que vise rendimentos permanentes. Em 
áreas com declividades acima de $25^{\circ}$ a suscetibilidade à erosão é extremamente forte e o uso agrícola não é recomendado. No presente artigo, na bacia em análise estas áreas totalizam $26,27 \mathrm{~km}^{2}$.

\section{RESULTADOS E DISCUSSÕES}

As FIGURAs 5 e 6 apresentam respectivamente a espacialidade do conjunto e a coleção de mapas por categoria de APP delimitada na bacia do rio Sagrado, enquanto que na TABELA 2 verifica-se sua quantificação.

A partir destes resultados pode-se destacar a existência de dois grupos de APP's: o primeiro representado pelo conjunto das categorias $1,2,3$ e 8 com $51,9 \%$ do total mapeado, e um segundo representados pelo conjunto das categorias $4,5,6 \mathrm{e}$ 7, $\operatorname{com} 48,1 \%$ do total das APP's da bacia.

A principal função do primeiro grupo (nascentes, mata ciliar, entorno de reservatórios e mangues) é a de preservar os recursos hídricos tanto em questão de qualidade quanto quantidade. Enquanto que o segundo grupo (topos de morro e montanha, linhas de cumeada e vertentes com declividades acima de $45^{\circ}$ ) tem como principal função a preservação das vertentes do desenvolvimento de processos erosivos e de movimentos de massa.

Uma das principais preocupações que se deve ter é a da preservação das nascentes dos cursos d'água, que conforme Calheiros et al. (2004) "a nascente ideal é aquela que fornece água de boa qualidade, abundante e contínua, localizada próxima do local de uso e de cota topográfica elevada, possibilitando sua distribuição por gravidade, sem gasto de energia". Segundo esses autores, as nascentes preservadas trazem benefícios ao ambiente como o controle de erosão do solo além de minimizar a contaminação química (agrotóxicos) e biológica (excrementos de animais) da água. 
Utilização do Sig na Delimitação das Áreas de Preservação Permanente (APP's) na Bacia do Rio Sagrado (Morretes/PR) Alexei Nowatzki, Leonardo José Cordeiro Santos, Eduardo Vedor de Paula

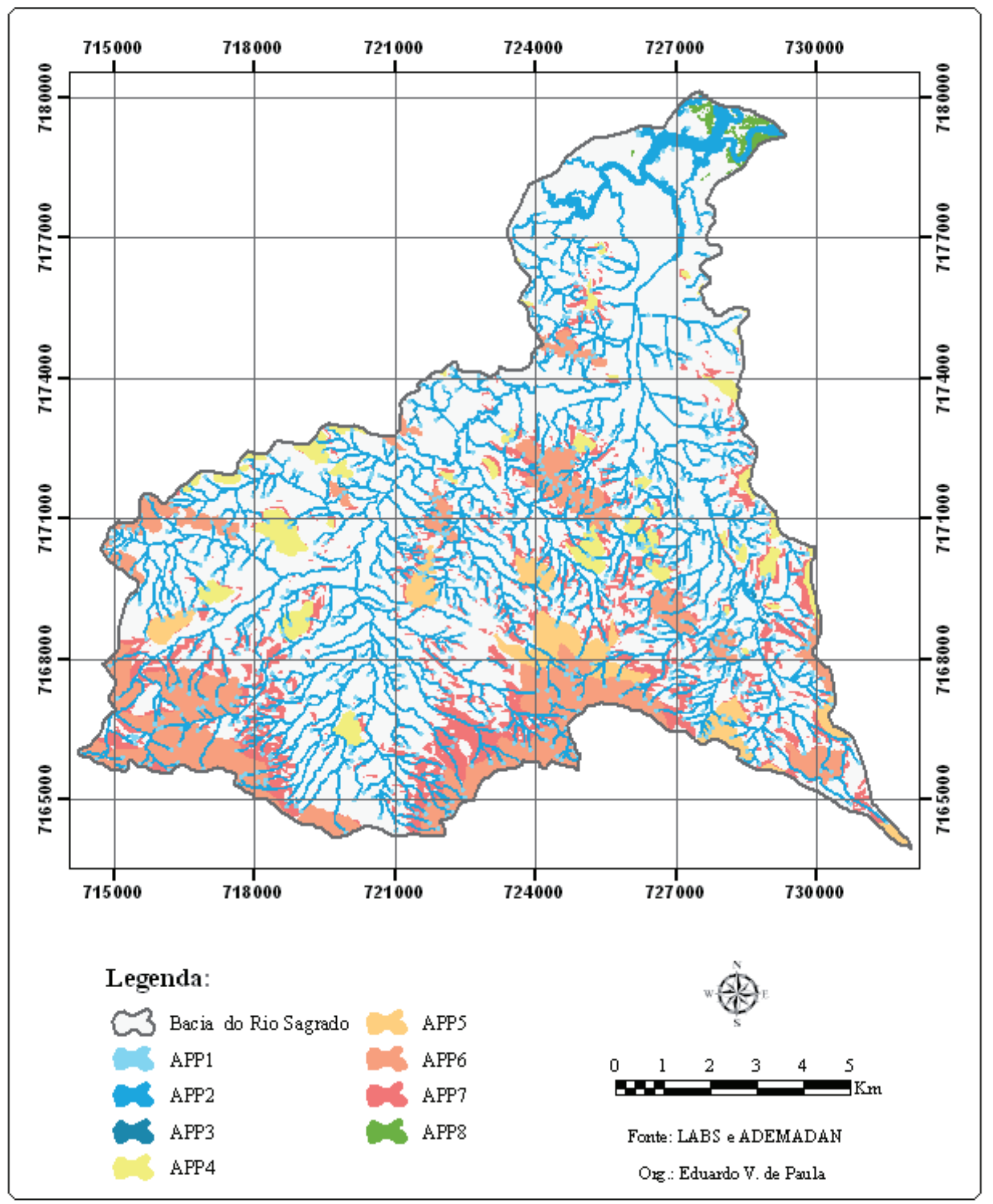

FIGURA 5: Conjunto das APP's delimitadas na bacia hidrográfica do rio Sagrado, (Morretes) Paraná. 
Utilização do Sig na Delimitação das Áreas de Preservação Permanente (APP's) na Bacia do Rio Sagrado (Morretes/PR) Alexei Nowatzki, Leonardo José Cordeiro Santos, Eduardo Vedor de Paula

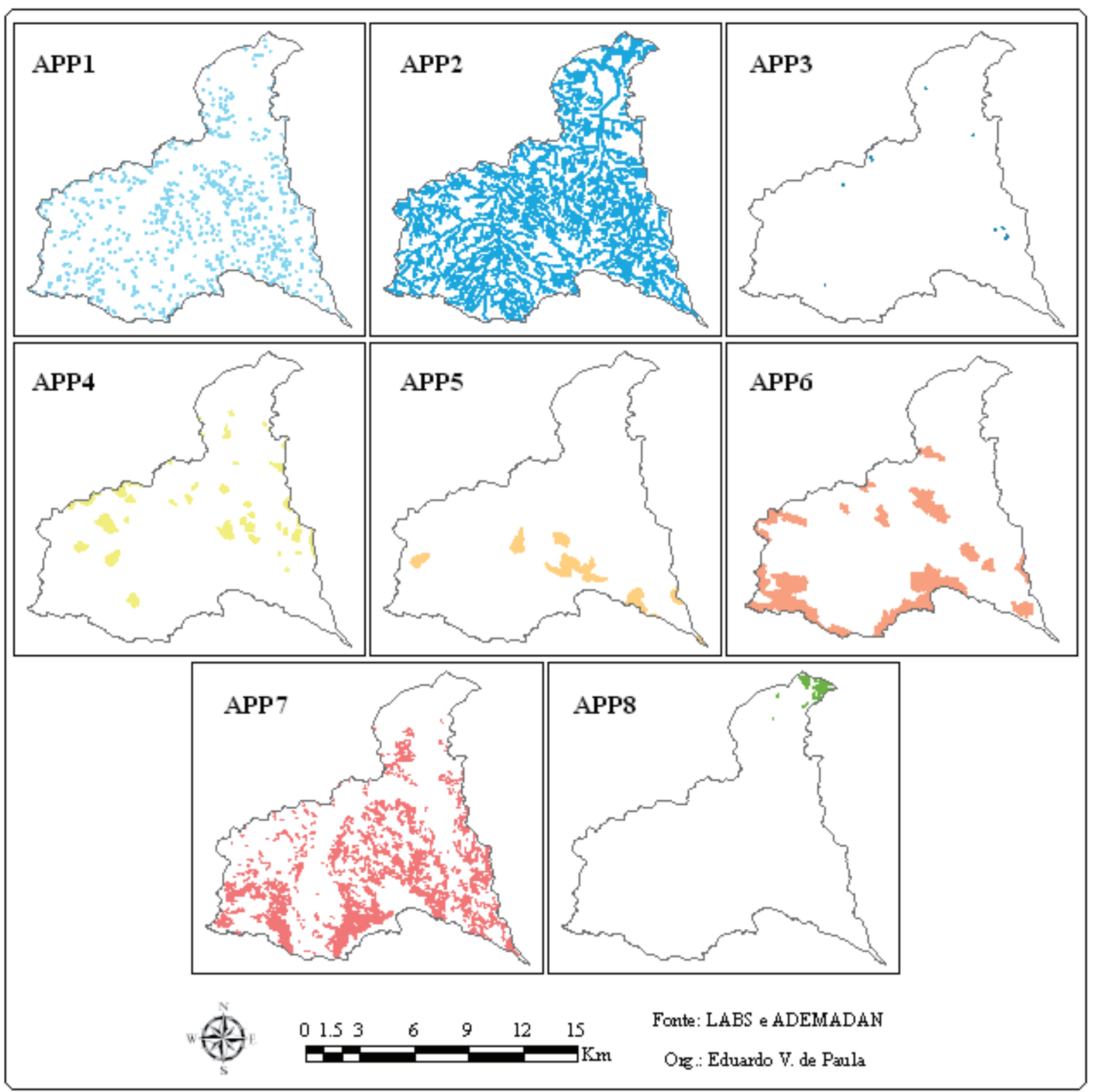

FIGURA 6: Coleção de mapas das APP's delimitadas na bacia hidrográfica do rio Sagrado (Morretes) Paraná. 
Utilização do Sig na Delimitação das Áreas de Preservação Permanente (APP's) na Bacia do Rio Sagrado (Morretes/PR)

Alexei Nowatzki, Leonardo José Cordeiro Santos, Eduardo Vedor de Paula

TABELA 2: Extensão das APP's por categoria na bacia hidrográfica do rio Sagrado.

\begin{tabular}{c|c|c|c}
\hline CÓDIGO APP & CATEGORIA & ÁREA $\left(\mathbf{K M}^{\mathbf{2}}\right)$ & $\mathbf{\%}$ \\
\hline APP1 & Nascentes & 5,66 & 8,35 \\
\hline APP2 & Rios & 28,93 & 42,68 \\
\hline APP3 & Represas & 0,05 & 0,07 \\
\hline APP4 & Topo de Morro & 4,65 & 6,86 \\
\hline APP5 & Topo de Montanha & 3,72 & 5,49 \\
\hline APP6 & Linhas de Cumeada & 13,35 & 19,70 \\
\hline APP7 & Declividade $>45^{\circ}$ & 10,86 & 16,02 \\
\hline APP8 & Mangues & 0,56 & 0,83 \\
\hline Total (APP) & Todas & $\mathbf{6 7 , 7 8}$ & $\mathbf{1 0 0 , 0 0}$ \\
\hline
\end{tabular}

Outra categoria que merece atenção é a mata ciliar. Andrade e Romero (2005) apresentam algumas de suas principais funções como "manter o equilíbrio hidrológico por meio: da estabilização das ribanceiras do rio através da manutenção do emaranhado de raízes; do controle do aporte de nutrientes e de produtos químicos aos cursos d'água; da filtragem e do controle da alteração da temperatura para o ecossistema aquático; da formação de barreiras para o carregamento de sedimentos para os cursos d'água evitando o assoreamento das micro-bacias hidrográficas". Eles complementam argumentando que as matas ciliares "são fundamentais para garantir a quantidade e qualidade da água em nossos rios, represas e lagos, além de proporcionar alimentação para os peixes e outros organismos vivos aquáticos".

Todavia, no âmbito de projetos ambientais voltados à estabilidade da paisagem e que contemplem significativas porções serranas, a exemplo do Programa CAD, o segundo grupo de APP's merece destaque. Isto porque a intensificação das intervenções antrópicas em áreas de alta suscetibilidade à ocorrência de processos erosivos e de movimentos de massa, situadas nas localidades de topo de morros, montanhas, linhas de cumeada e declives acentuados, tende a ampliar a disponibilização de sedimentos à rede de drenagem.

\section{CONSIDERAÇÕES FINAIS}

As técnicas utilizadas em SIG foram eficientes para o desenvolvimento do presente trabalho e a partir da metodologia empregada, o mapeamento das APP's pôde ter resultados satisfatórios, da mesma forma que Paula e Cunico (2008) obtiveram para o mapeamento de APP's para o Rio Pequeno em Antonina (PR).

Visando a melhor interpretação do relevo, na identificação das linhas de cumeada, morros ou montanhas, recomenda-se a utilização de um banco de dados relativo às bacias hidrográficas contíguas, contendo as curvas de nível, pontos cotados e hidrografia, pois em alguns casos a base dos divisores de água está situada na encosta de fora da bacia hidrográfica analisada. Na definição de morro, montanha e linha de cumeada deve-se estipular qual é o topo mais alto e entender o contexto hidrográfico que regem as vertentes analisadas para definir a base, pois esta deve ser entendida pela contribuição dos canais de drenagem das vertentes relativas ao topo.

Entretanto, é importante salientar que esta proposta metodológica visa subsidiar o desenvolvimento de projetos de planejamento e avaliação ambiental, cuja amplitude da área de abrangência impossibilite a delimitação das APP's 
dentro de cada propriedade rural. Portanto, para efeito de atendimento da legislação ambiental descrita no presente artigo e averbação das APP's e Reserva Legal, é indispensável que as delimitações sejam efetuadas em campo.

$\mathrm{Na}$ continuidade do Programa CAD pretende-se utilizar os resultados desse trabalho na avaliação de grau de conservação de cada tipo de APP, bem como na identificação da evolução da ocupação humana sobre as mesmas nos anos de 1952, 1980, 1999 e 2005 para os quais se dispõem de mapeamento de cobertura vegetal e uso da terra. Esses resultados também subsidiarão a delimitação das áreas prioritárias à recuperação ambiental na bacia do rio Sagrado, conforme estudo realizado por Paula e Santos (2009).

\section{REFERÊNCIAS}

ANDRADE, L. M. S. de; ROMERO, M. A. B. A importância das áreas ambientalmente protegidas nas cidades. In: XI ENCONTRO NACIONAL DE PÓS-GRADUAÇÃO E PESQUISA EM PLANEJAMENTO URBANO E REGIONAL ANPUR. Salvador/BA, 2005. Anais... Salvador/BA, 2005.

BOLDRINI, E. B.; PAULA, E. V. O Programa CAD (Contaminantes, Assoreamento e Dragagem no Estuário de Paranaguá) e a Recuperação de Bacias Hidrográficas para Mitigar o Processo de Assoreamento. In: BOLDRINI, E. B.; SORAES, C. R.; PAULA, E. V.(Org.). Dragagens Portuárias no Brasil: engenharia, tecnologias e meio ambiente. Antonina: ADEMADAN e UNIBEM. 2008.

BRASIL. Lei Federal $n^{\circ} 4771 / 65$, de 15 de setembro de 1965, alterada pela Medida Provisória no 2.166 67, de 24 de agosto de 2001. Brasília, DF: Congresso Nacional, 2001.

- Resolução do CONAMA 302, de 20

de março de 2002. Dispõe sobre os parâmetros, definições e limites de Áreas de Preservação Permanente de reservatórios artificiais e o regime de uso do entorno. Brasília, DF: Congresso Nacional, 2002a.

. Resolução do CONAMA 303, de 20 de março de 2002, Dispõe sobre os parâmetros, definições e limites de Áreas de Preservação Permanente. Brasília, DF: Congresso Nacional, 2002b.

CALHEIROS, R. de O.; TABAI, F. C. V.; BOSQUILIA, S. V.; CALAMARI, M. Preservação e recuperação das nascentes (de água e de vida). Comitê das Bacias Hidrográficas dos Rios Piracicaba, Capivarí e Jundiaí - CTRN. Piracicaba, 2004

CHRISTOFOLETTI, A. Geomorfologia. São Paulo: Edgar Blucher, Universidade de São Paulo, 1974.

MASCARENHAS, L. M. A.; FERREIRA, M. E.; FERREIRA L. G. Sensoriamento remoto como instrumento de controle e proteção ambiental: análise da cobertura vegetal remanescente na bacia do rio Araguaia. Revista Sociedade \& Natureza, V. 21, N. 1, Uberlândia, 2009. DOI: 10.1590/S198245132009000100001

PAULA, E. V.; CUNICO, C. Caracterização sócioambiental das bacias hidrográficas que drenam para a Baía de Antonina e Paranaguá (Projeto CAD - Fase 3). Antonina: ADEMADAN, 2006. 54 p. Relatório Técnico Terminais Portuários Ponta do Felix, Terminais Marítimos da Cattalini e Terminais de Contêineres de Paranaguá.

NEVES, C. B.; CASTRO, S. S.; SANTOS, N.; BORGES, R. O.; Análise das relações entre solos, relevo e a legislação ambiental para a delimitação das Áreas de Preservação Permanente: o exemplo da alta bacia do ribeirão João Leite, Estado de Goiás. Revista Brasileira de Geomorfologia, v.10, n.1, 2009. p. $3-21$.

IEMA/ES (Instituto Estadual de Meio Ambiente do Espírito Santo). Áreas de Preservação Permanente. 2010. Disponível em: $<$ http://www.meioambiente.es.gov.br/default.asp $>$. Acesso em: 30 mar. 2010. 
Utilização do Sig na Delimitação das Áreas de Preservação Permanente (APP’s) na Bacia do Rio Sagrado (Morretes/PR)

Alexei Nowatzki, Leonardo José Cordeiro Santos, Eduardo Vedor de Paula

PAULA, E. V.; CUNICO, C. O assoreamento das baías de Antonina e Paranaguá e a gestão de suas bacias hidrográficas. In: BOLDRINI, E. B.; SORAES, C. R.; PAULA, E. V.(Orgs.). Dragagens Portuárias no Brasil: Licenciamento e Monitoramento Ambiental. Antonina: Governo do Estado do Paraná; SEMA/PR; ADEMADAN; UNIBEM. 2007.

PAUlA, E. V.; CUNICO, C. Delimitação das áreas prioritárias à recuperação ambiental na bacia hidrográfica do Rio Pequeno (Antonina - PR) In: BOLDRINI, E. B.; SORAES, C. R.; PAULA, E. V. (Org.) Dragagens Portuárias no Brasil: Engenharia, Tecnologia e Meio Ambiente. Antonina: ADEMADAN, UNIBEN, MCT. 2008.

PAULA, E. V.; SANTOS, L. J. C. Mapeamento da Suscetibilidade a Processos Erosivos por meio de SIG, como subsidio ao Monitoramento do Assoreamento da Baía de Paranaguá: estudo de caso da bacia hidrográfica do Rio Pequeno. In: VIII SIMPÓSIO NACIONAL DE CONTROLE DE EROSÃO. São Paulo/SP. Anais... São Paulo/SP, CD - ROM. Trabalho Completo. 2009.

PAULA, E. V.; CUNICO, C.; BOLDRINI, E. B. Controle do assoreamento e dos contaminantes por meio da gestão de bacias hidrográficas para o planejamento das dragagens portuárias na Baía de Antonina/Paraná/Brasil. RAE'GA: O espaço geográfico em análise. Curitiba, n.12, 2006. p.195210.

PARANÁ. Secretaria de Estado do Meio Ambiente e Recursos Hídricos. Programa Floresta Atlântica. Mapeamento da Floresta Atlâtica do Estado do Paraná. Relatório final. Curitiba, 2002.

PERICO, E; CEMIN, G. Planejamento do uso do solo em ambiente SIG: Alocação de um distrito industrial no município de Lajeado, RS, Brasil. Estudos Geográficos 4(1), Rio Claro, 2006. p. 41 52.
RIBEIRO, C. A. A. S.; SOARES, V. P.; OLIVEIRA, A. M. S.; GLERIANI, J. M. O desafio da delimitação de áreas de preservação permanente. Rev. Árvore [online]. 2005, vol.29, n.2, p. 203 - 212. Disponível em: $\quad<$ http://www.scielo.br/scielo.php?script=sci arttext\&pid=S0100-67622005000200004\&lng=pt\& nrm=iso $>$. Acesso em: 29 mar. 2010. DOI: 10.1590/ S0100-67622005000200004

TEIXEIRA, A. L. A; CHRISTOFOLETTI A. Sistema de Informações Geográficas: dicionário ilustrado. São Paulo: Editora Hucitec, 1997. 